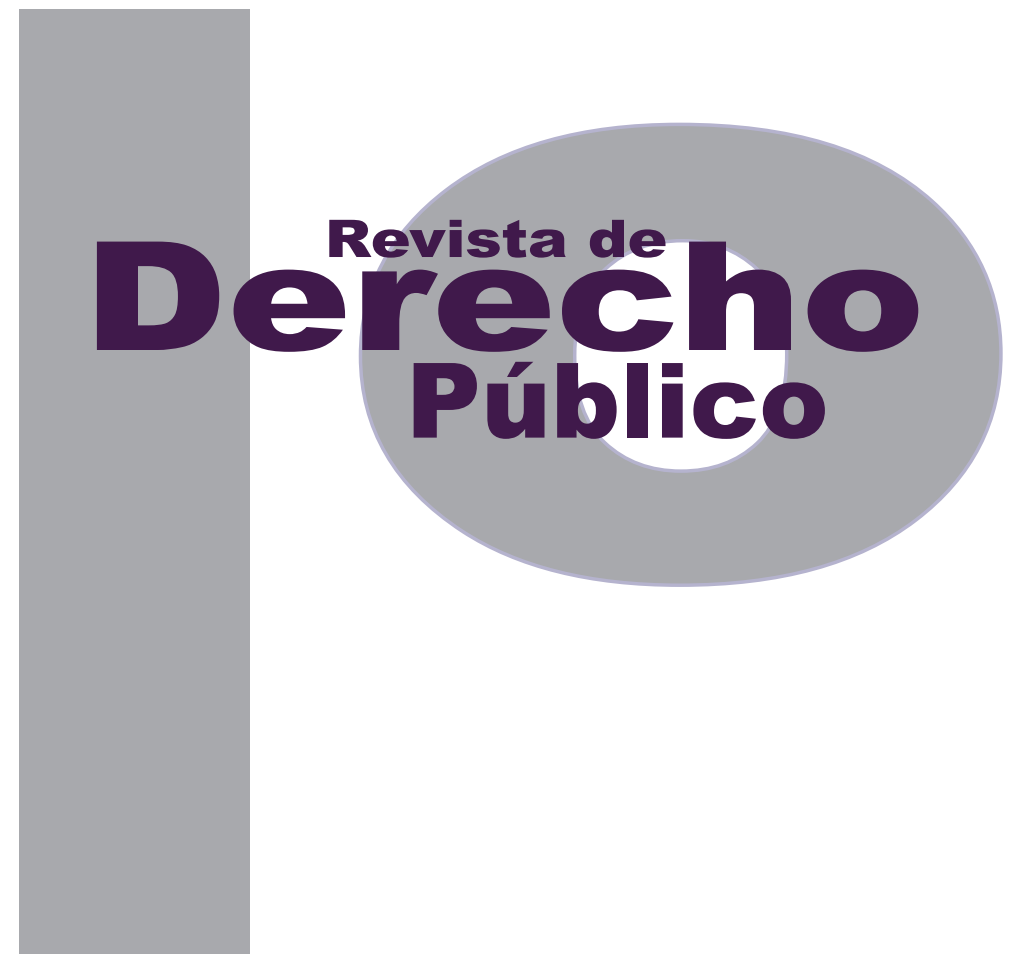

\title{
LA RESTITUCIÓN DE TIERRAS. ACCIÓN CONSTITUCIONAL PARA LA PROTECCIÓN DE UN DERECHO SOCIAL FUNDAMENTAL
}

\author{
Oscar Humberto Ramírez Cardona
}

Universidad de los Andes

Facultad de Derecho

Revista de Derecho Público N. ${ }^{\circ} 31$

Julio - Diciembre de 2013. ISSN 1909-7778 


\title{
La restitución de tierras. Acción constitucional para la protección de un derecho social fundamental*
}

\author{
Oscar Humberto Ramírez Cardona** \\ "Todos compartimos con el Gobierno la aspiración de un país que deje de ser reconocido \\ internacionalmente por su triste récord de derechos humanos. \\ Pero eso se logra cambiando la realidad, no retocando la imagen".
}

César Rodríguez Garavito.

\begin{abstract}
RESUMEN
Uno de los aspectos consagrados en la Ley 1448 de 2011 para la atención, asistencia y reparación integral a las víctimas del conflicto armado interno, que ha generado mayores expectativas es, precisamente, el proceso de restitución de tierras despojadas o abandonadas, establecido como uno de los mecanismos de reparación integral. Diversas inquietudes surgen en relación con la aplicación de las normas de restitución que conllevan el cambio en la forma de atender las controversias sobre la propiedad, generalmente resueltas a partir de las normas de derecho civil y excepcionalmente mediante el derecho agrario, de escaso desarrollo en el derecho colombiano.
\end{abstract}

\begin{abstract}
The land restitution process established by the law 1448 of 2011 is the most important issue of the internal war victims' reparation. But there are some difficulties related with the norms' application. The law implies changes in the way civil and agrarian law is use to handle property conflicts.

The present paper states that the restitution process is a constitutional action that looks out for the protection of the fundamental social rights of victims. This protection implies affirmative actions in favor of the victims and several responsibilities for the State and the particulars that disturbed or violated the right protected.
\end{abstract}

Cómo citar este artículo: Ramírez Cardona, O. H. (Diciembre, 2013). La restitución de tierras. Acción constitucional para la protección de un derecho social fundamental. Revista de Derecho Público, 31 ..

Abogado de la Universidad Santo Tomás. Magíster en Derecho de la Universidad de los Andes. Magistrado de la Sala Civil Especializada en Restitución de Tierras del Tribunal de Bogotá. Catedrático en las universidades Santo Tomás, del Rosario y de los Andes. Correo: teorami@yahoo.com 
El presente escrito sostiene la tesis que el proceso de restitución es una acción constitucional a través de la cual se procura la protección de un derecho social fundamental, que implica unas acciones afirmativas a favor de las víctimas, y responsabilidades para el Estado y para los particulares que vulneraron o se beneficiaron de la vulneración del derecho protegido.

Se argumenta que el carácter constitucional de la restitución se ajusta a las normas internacionales que exigen un trámite expedito y efectivo para la protección de los derechos fundamentales y otorga especiales potestades al juez para el logro del fin propuesto. Finalmente, se sugieren los criterios interpretativos que deben guiar el proceso.

PALABRAS Clave: restitución, justicia transicional, víctima, desplazamiento, reparación integral, derecho social fundamental, Principios Deng, Principios Pinheiro, pro homine.
Additionally, it is argue that as a constitutional action, the land restitution process adopts international law issues that demand for effective and prompt actions toward the protection of fundamental rights and grants to the judges some non-communes powers to accomplish the restitution objectives. Finally, this paper will articulate the special situations that confirm the assertions made.

KEY WORDS: restitution, transitional justice, victim, displacement, integral reparation, social fundamental right, Deng Principles, Pinheiro Principles, pro homine. 


\section{SUMARIO}

Introducción - I. LOS DERECHOS FUNDAMENTALES Y LOS DERECHOS SOCIALES FUNDAMENTALES. CONCEPTOS BÁSICOS - II. LOS DERECHOS FUNDAMENTALES DE LOS DESPLAZADOS DEL CONFLICTO ARMADO COLOMBIANO Y EL DERECHO A LA RESTITUCIÓN DE TIERRAS DESPOJADAS O ABANDONADAS COMO DERECHO SOCIAL FUNDAMENTAL. DESARROLLO JURISPRUDENCIAL - III. EL DERECHO A LA RESTITUCIÓN DE TIERRAS ABANDONADAS O DESPOJADAS COMO CONSECUENCIA DEL CONFLICTO ARMADO INTERNO ES UN DERECHO SOCIAL FUNDAMENTAL - IV. EL PROCEDIMIENTO DE RESTITUCIÓN ESTABLECIDO EN LA LEY SE AJUSTA A LA EXIGENCIA DE LA NORMATIVIDAD INTERNACIONAL EN CUANTO A UN MECANISMO EXPEDITO PARA LA PROTECCIÓN DE LOS DERECHOS

FUNDAMENTALES - V. EL PROCESO DE RESTITUCIÓN DE TIERRAS DESPOJADAS O ABANDONADAS COMO UN RECURSO CONSTITUCIONAL. CARACTERÍSTICAS - VI. IMPLICACIONES DE CONCEBIR EL PROCESO DE RESTITUCIÓN COMO UNA ACCIÓN CONSTITUCIONAL MEDIANTE LA CUAL SE PROTEGE UN DERECHO SOCIAL FUNDAMENTAL - VII. CARÁCTER MIXTO DEL PROCESO. EL TRÁMITE ADMINISTRATIVO - VIII. CONCLUSIONES - Bibliografía. 
Introducción

El proceso de restitución de tierras despojadas o abandonadas, consagrado en la Ley 1448 de 2011, constituye una de las medidas de reparación más trascendentales emitidas hasta la fecha, dentro del marco de la justicia transicional adoptado en Colombia con el "fin último de lograr la reconciliación nacional y la paz duradera y sostenible" para los colombianos. Lo anterior se confirma por el hecho constatado de que el conflicto armado interno que ha vivido el país durante más de cincuenta años está atravesado por la disputa por la tierra y por el dominio del territorio; no en vano se habla de 6.6 millones de hectáreas despojadas o abandonadas que equivalen al $15.4 \%$ del total de la superficie agropecuaria del país. ${ }^{1}$ Resulta igualmente indicativa del conflicto, la incapacidad de la institucionalidad para regular el acceso, distribución y adecuada explotación de la tierra, así como para garantizar su preservación conforme a derecho y la absoluta inoperancia de la jurisdicción agraria. La hondura de la problemática mencionada, el importante porcentaje de población afectada y la significación que tiene para el fin último de la justicia transicional señalado, han llevado a considerar a la restitución como un derecho fundamental.

La restitución de tierras, instrumento de reparación integral consagrado en el Título IV de la Ley 1448 de 2011, comprende "la restitución

GARAY SALAMANCA, Luis Jorge y VARGAS VALENCIA Fernando. Memoria y reparación. Elementos para una justicia transicional pro víctima. Bogotá: Universidad Externado de Colombia, 2012, p. 16. jurídica y material del inmueble despojado", ${ }^{2}$ o abandonado ${ }^{3}$ y tratándose de baldíos “la adjudicación del derecho de propiedad del baldío"4 si se cumplieron las condiciones para ello durante el despojo o el abandono del predio. Ante la imposibilidad de restitución o adjudicación del predio efectivamente despojado o abandonado, la Ley prevé el cumplimiento con otro predio equivalente y como última posibilidad consagra la compensación económica a la víctima del despojo o abandono.

La justicia transicional es entendida por la misma Ley, en su artículo 8, como:

Ios diferentes procesos y mecanismos judiciales o extrajudiciales asociados con los intentos de la sociedad por garantizar que los responsables de las violaciones contempladas en el artículo 30 de la presente Ley, rindan cuentas de sus actos, se satisfagan los derechos a la justicia, la verdad y la reparación integral a las víctimas, se lleven a cabo las reformas institucionales necesarias para la no repetición de los hechos y la desarticulación de las estructuras armadas ilegales, con el fin último de lograr la reconciliación nacional y la paz duradera y sostenible.

$2 \quad$ Art. 72, Ley 1448 de 2011.

3 Los artículos 28, numeral 9 y 72, incisos 2, 4 y 5 de la Ley 1448 de 2011 utilizan de manera exclusiva las expresiones "despojo" o "despojado", sin embargo, la Corte Constitucional en sentencia C-715/2012, L. Vargas, las declaró exequibles en el entendido de que incluyen tanto a las víctimas de despojo como a las víctimas forzadas al abandono de sus bienes.

$4 \quad$ Art. 72, Ley 1448 de 2011. 
La Corte Constitucional la concibe como:

(...) una institución jurídica a través de la cual se pretende integrar diversos esfuerzos, que aplican las sociedades para enfrentar las consecuencias de violaciones masivas y abusos generalizados o sistemáticos en materia de derechos humanos, sufridos en un conflicto, hacia una etapa constructiva de paz, respeto, reconciliación y consolidación de la democracia, situaciones de excepción frente a lo que resultaría de la aplicación de las instituciones penales corrientes. ${ }^{5}$

De acuerdo con los Principios de Chicago sobre justicia postconflicto, la justicia transicional "debe revelar toda la verdad que sea posible, proveer la mayor cantidad de reparaciones que se puedan pagar; y asegurar el grado de reconciliación más alto alcanzable."

En el caso colombiano los objetivos de la justicia transicional, y de manera concreta el de la restitución de tierras, deben procurarse en medio de un conflicto que no cesa, frente a ostensibles dificultades para alcanzar la justicia y con la incertidumbre que despierta una institucionalidad de nuevo cuño.

La institucionalidad establecida por la Ley 1448 de 2011 para la restitución de tierras no es ajena a las perplejidades indicadas. La Ley en comento crea un procedimiento para adelantar la restitución y señala los responsables de llevarla a cabo, indicando, en lo que hace al trámite judicial a los jueces y magistrados civiles, lo que aunado a las escasas reglas incorpora-

5 CConst., C-052/2012, N. Pinilla. das en la normativa pudiera hacer pensar que estamos frente a un proceso de naturaleza civil a pesar de no realizarse una remisión expresa a un procedimiento o trámite específico, como si lo hace, a manera de ejemplo, la Ley 975 de $2005^{6}$ sobre “justicia y paz”, hermana melliza de la de reparación de víctimas.

Es en esta perspectiva en la que surgen las inquietudes sobre la naturaleza del proceso de restitución de tierras y respecto de las normas que le serían aplicables en adición o complemento a las propias de la Ley comentada, lo cual constituye el objeto de este escrito.

Por tanto, se brindarán argumentos para sostener que el proceso de restitución de tierras es una acción constitucional que procura proteger un derecho social fundamental. Para demostrar lo anterior se darán los conceptos básicos de derecho fundamental y derecho social fundamental; se mostrará el surgimiento y desarroIlo que han tenido los derechos fundamentales reconocidos a las víctimas del conflicto armado colombiano y de manera especial a los desplazados internos; y se precisará el surgimiento, naturaleza y alcance del derecho fundamental a la restitución. Por último, se determinarán las características del proceso de restitución de la Ley 1448 de 2011 como proceso constitucional autónomo y se hará referencia a las implicaciones que conlleva tal concepción.

6 Artículo 62. Complementariedad. Para todo lo no dispuesto en la presente Ley se aplicará la Ley 782 de 2002 y el Código de Procedimiento Penal. 
I. LOS DERECHOS FUNDAMENTALES $Y$ LOS DERECHOS SOCIALES FUNDAMENTALES. CONCEPTOS BÁSICOS

Al concepto de derechos fundamentales puede llegarse a través de tres criterios: formal, material y procesal. ${ }^{7}$

De acuerdo con el primero serán derechos fundamentales aquellos que expresamente la Constitución ha señalado como tales. Para el caso colombiano serían los contemplados en el Capítulo I, Título II de la Constitución Nacional, sin embargo, la doctrina y la misma jurisprudencia tienen por tales, otros incorporados en la Constitución por fuera del capítulo precitado.

Con base en el concepto material, los derechos fundamentales son derechos humanos liberales del individuo, constitucionalizados o positivizados mediante su incorporación en la Constitución, pero con tal criterio quedan excluidos los derechos a acciones positivas del Estado, esto es, los derechos sociales o derechos sociales fundamentales.

El criterio procesal vincula los dos anteriores y pregona que, dada la importancia de los derechos fundamentales, no pueden dejarse a la voluntad de la mayoría legislativa, siendo por tanto competencia del poder constituyente. En su componente formal el constituyente, con su margen de consideración, podría incorporar derechos sociales como fundamentales; por su

7 ALEXY, Robert. Los derechos fundamentales. En: Tres escritos sobre los derechos fundamentales y la teoría de los principios. Bogotá: Universidad Externado de Colombia, 2003, p. 21-30. parte, el componente material implica que el concepto de derecho fundamental se construya recurriendo al de derechos humanos.

Como explica Alexy, los derechos fundamentales incorporados al derecho positivo son objeto de interpretación, y dado su carácter abierto e indeterminado "queda un amplio espacio para que jueguen viejos y nuevos argumentos relativos a los derechos humanos". 8 Adicionalmente, la influencia de tales derechos en la estructura de la sociedad hace que su interpretación tenga amplias implicaciones políticas.

Destaca también el tratadista alemán la importancia de los derechos fundamentales al empoderar a las personas en procura de protección a través de procedimientos adecuados para ello. ${ }^{9}$

Rodolfo Arango acude a la definición de Alexy sobre derecho fundamental por las ventajas que le atribuye en cuanto a brevedad, grado de generalidad y por su anclaje en la teoría política. De acuerdo con la alabada definición los derechos fundamentales son "posiciones tan importantes que su otorgamiento o no otorgamiento no puede quedar en manos de la simple mayoría parlamentaria". ${ }^{10}$

A partir de la anterior definición Arango sostiene que los derechos fundamentales "son derechos subjetivos con un alto grado de importancia”, el

\footnotetext{
$8 \quad$ Ibídem, p. 35.

$9 \quad$ Ibídem, p. 37

10 ARANGO RIVADENEIRA, Rodolfo. El concepto de los derechos sociales fundamentales. $2^{\mathrm{a}}$ ed. Bogotá: Legis, 2012, p. 31.
} 
derecho subjetivo a su vez implica una norma jurídica (M1), una obligación jurídica (M2) y una posición jurídica ${ }^{11}(\mathrm{M} 3)$, solo que para el caso concreto las normas son sobre derechos fundamentales, las obligaciones jurídicas son fundamentales y las posiciones jurídicas “aquellas que solo pueden ser obtenidas de las disposiciones de derechos fundamentales mediante una justificación jurídica fundamental correcta". ${ }^{12} \mathrm{~A}$ las anteriores características propias de los derechos subjetivos adiciona Arango el grado de importancia del derecho (M4) que encierra un juicio de valor ligado a la proposición normativa.

Los derechos fundamentales en general pueden ser explícitos, cuando aparecen expresamente en el texto constitucional, o adscriptos por vía de interpretación, cuando cuentan con una correcta justificación constitucional, por ejemplo, cuando su negación contradice el sistema jurídico visto como un todo. ${ }^{13}$

El mismo Rodolfo Arango define el derecho social fundamental como derecho subjetivo con un alto grado de importancia y "de prestación en su sentido estrecho, es decir, derechos generales positivos a acciones fácticas del Estado". ${ }^{14}$

11 De acuerdo con Arango, la posición jurídica desde la perspectiva lógica implica que un individuo puede exigir algo de otro; desde la perspectiva sustancial da a entender la situación que ocupa un individuo dentro del orden normativo que debe ser reconocida y protegida, y desde la perspectiva política significa que el individuo es tomado en serio. Las posiciones jurídicas tienen de adicional a las normas y los deberes que "pueden ser generadas por la vía de la argumentación a partir de una o varias normas" (ob. cit., p. 20).

12 Ibídem, p. 32.

13 Ibídem, p. 41

14 Ibídem, p. 38
Similar a la caracterización del derecho fundamental, el derecho social fundamental implica la norma jurídica (M1), la obligación jurídica (M2), la posición jurídica (M3), el grado de importancia (M4) y el carácter general positivo (M5).

El derecho social fundamental se basa por lo general en normas hipotéticas, ya que para saber cuándo está el Estado obligado a algo respecto de una persona debe verificarse una condición respecto de ella, ${ }^{15}$ es, por tanto, un derecho condicionado, para lo que se debe tener en cuenta lo afirmado por Alexy, citado por Arango: "son derechos del individuo frente al Estado a algo que -si el individuo poseyera medios financieros suficientes y se encontrase en el mercado una oferta suficiente- podría obtenerlo directamente de particulares". ${ }^{16}$

La concepción del derecho social fundamental expuesta por Arango, la cual acogemos para efectos del presente escrito, se funda en una "relación real" entre derechos y mercado que parte de afirmar que "Si bien la libertad y la igualdad son fines deseables, las diferencias de hecho entre las personas impiden la realización de los fines de la libertad y la igualdad". ${ }^{17}$

El derecho social fundamental implica unas condiciones formales y materiales. Las primeras, según el tratadista que venimos siguiendo, surgen cuando el Estado teniendo la posibilidad jurídica y fáctica de hacer algo deja de hacer-

\footnotetext{
15 Ibídem, p. 136.

16 Ibídem, p. 137.

17 Ibídem, p. 146.
} 
lo, originando tal omisión la amenaza de daño sin justificación a una persona. ${ }^{18}$ Las segundas, esto es, las condiciones materiales, se producen cuando quien hace valer una acción fáctica positiva del Estado se encuentra en una situación de necesidad que anule o afecte gravemente su libertad y su igualdad reales. ${ }^{19}$ Estas condiciones materiales pueden derivarse de factores físicos o psíquicos, o de factores económicos que Arango circunscribe a la falta de medios económicos o al déficit del mercado.

Pero quizá lo más importante para efectos del presente escrito es determinar la justiciabilidad de los derechos sociales fundamentales, la cual, como lo explica Arango, es negada por algunos por cuanto "la prestación contenida en ellos es tan general, que no es posible deducir una pretensión jurídica concreta por vía de interpretación". ${ }^{20}$ Consecuencialmente, dice Arango, solo serían justiciables los derechos fundamentales de libertad.

Sin embargo, Arango a través de su erudito y apasionante escrito se encarga de demostrar que los derechos fundamentales sí son justiciables, a partir de las que señala como condiciones formales y materiales de estos. Al respecto dice el autor en cita: "Las condiciones formales de los derechos sociales fundamentales pueden resumirse así: si el Estado tiene la posibilidad jurídica y fáctica de hacer algo, pero deja de

18 Ibídem, p. 155.

19 Ibídem, p. 156

20

E-W Böckenförde, citado por Arango, ob. cit., p. 116. hacerlo y tal omisión, en las circunstancias concretas, amenaza sin justificación con dañar a una persona, entonces existe el derecho de tal persona a una acción fáctica positiva del Estado". ${ }^{21}$ (Resaltado mío).

Añade luego Arango que a las condiciones formales de los derechos sociales fundamentales se agrega una condición material: "Quien hace valer un derecho a una acción fáctica positiva del Estado tiene que encontrarse en una situación de necesidad que anule o afecte gravemente su libertad y su igualdad reales". Argumenta el autor que en las constituciones que adoptan un Estado Social de Derecho "toman por hecho que hay factores que pueden poner en peligro" los presupuestos de libertad o igualdad del individuo, y que por tanto "su función esencial consiste, así, en proteger al individuo de los riesgos naturales y sociales a que está expuesto, de forma que este pueda desarrollar en la mayor medida posible sus potencialidades". ${ }^{22}$

Entiende por tanto Arango que las obligaciones positivas del Estado en materia de los derechos sociales fundamentales están sujetas al principio de subsidiariedad y a las condiciones materiales que las activan. De acuerdo con el primero "el Estado sólo está obligado a actuar positivamente cuando la persona se encuentra en unas circunstancias personales o fácticas que afectan su vida autónoma y digna de manera no previsible ni soportable, esto es si se cumplen

21 Ibídem, p. 154

22 Ibídem, p. 156-157. 
las condiciones materiales y formales de los derechos sociales fundamentales". 23

Las condiciones materiales y sociales las circunscribe Arango a factores físicos y síquicos, y a los económicos. Refiriéndose a los primeros afirma, siguiendo al economista hindú premio Nobel de Economía: "No son la igualdad de bienes primarios ni la igualdad de recursos, los parámetros de justicia distributiva que toman en serio al ser humano... sino las capabilities las que permiten convertir a aquellos en libertad efectiva. Deben ser, por lo tanto, las capacidades actuales de la persona el criterio fundamental para el otorgamiento y la protección de derechos". ${ }^{24}$

En cuanto a los factores económicos, señala el autor tantas veces citado que la falta de medios materiales o situaciones de déficit de mercado Ilevan a que la persona no pueda satisfacer sus necesidades básicas fundamentales.

Por ser de absoluta relevancia para el presente estudio citamos la nota 184 del texto de Arango, que al referirse al déficit de mercado señala en relación con el derecho a la propiedad: “¿Qué sería del derecho a la propiedad sin posibilidades de protección y de realización? Los precios más bajos de las propiedades en las sociedades con un sistema de justicia ineficiente y con vioIencia (por ejemplo Colombia) demuestra que el ejercicio de los derechos de propiedad también presuponen medidas estatales positivas...". ${ }^{25}$

\footnotetext{
23 Ibídem, p. 158

24 Ibídem, p. 160.

25 Ibídem, p. 167.
}

Concluimos este aparte afirmando que los derechos sociales fundamentales son también justiciables de manera subsidiaria cuando se dan las condiciones formales y materiales que activan la obligación de acción del Estado.

\section{LOS DERECHOS FUNDAMENTALES DE LOS DESPLAZADOS DEL CONFLIC- TO ARMADO COLOMBIANO Y EL DERECHO A LA RESTITUCIÓN DE TIERRAS DESPOJADAS O ABANDONA- DAS COMO DERECHO SOCIAL FUNDAMENTAL. DESARROLLO JURISPRUDENCIAL}

Con anterioridad al año 2004 la Corte Constitucional había proferido un número importante de sentencias de tutela protegiendo derechos fundamentales invocados por personas desplazadas en el territorio nacional. Pero es la sentencia T-025, M. Cepeda, del año mencionado, el referente más importante en lo que hace a los derechos de los desplazados.

En primer lugar porque considera que la grave situación de desplazamiento da lugar a la declaración del "estado de cosas inconstitucional", entendido como aquella situación que "contraría la racionalidad implícita en el constitucionalismo", al causar una "evidente tensión entre la pretensión de organización política y la prolífica declaración de valores, principios y derechos contenidas en el Texto Fundamental y la diaria y trágica constatación de la exclusión de ese acuerdo de millones de colombianos". En la sentencia brinda la Corte las razones concretas 
para declarar el estado de cosas inconstitucional en el caso de los desplazados. Por lo demás, con base en dicha declaratoria la Corte Constitucional viene realizando actividades de seguimiento a las órdenes impartidas en la sentencia citada mediante autos en los que da nuevas órdenes o recomendaciones.

En segunda instancia, por cuanto incorpora de manera concreta y sistemática al derecho interno colombiano los Principios Rectores del Desplazamiento Forzado Interno (PRDFI), también conocidos como Principios Deng, originados en el Informe del Representante Especial del Secretario General de Naciones Unidas para el tema de los desplazamientos internos de personas, de 1988.

En tercer lugar, porque en dicha sentencia se confirma y sienta precedente en cuanto al nivel mínimo de satisfacción de los derechos constitucionales de las personas desplazadas que implica distinguir "entre (a) el respeto por el núcleo esencial de los derechos constitucionales fundamentales de los desplazados, y (b) la satisfacción, por parte de las autoridades, de ciertos deberes prestacionales derivados de los derechos reconocidos a nivel internacional y constitucional en cabeza de los desplazados".

Con fundamento en el segundo de los aspectos previamente mencionados, la Corte Constitucional señaló, en la sentencia que se viene analizando, que las circunstancias en que se encuentran los desplazados generan en las autoridades claras obligaciones de carácter prestacional, que necesariamente implican gasto público "lo cual no obsta para clasificar algunos de tales derechos como fundamentales" y fija como criterio para determinar esos "derechos de marcado contenido prestacional que forman parte del mínimo que siempre ha de ser garantizado a todos los desplazados" la conexidad "estrecha con la preservación de la vida en circunstancias elementales de dignidad como seres humanos distintos y autónomos" (artículos 1, 11, 12, 13, 14, 16 y 17, Constitución Política).

De manera que a partir de la sentencia T-025 podemos hablar claramente de unos derechos sociales fundamentales predicables de la población desplazada por el conflicto armado colombiano. De los derechos mencionados por la Corte en la referida sentencia destaco los siguientes:

1. El derecho a la familia y a la unidad familiar consagrado en los artículos 42 y 44 C. P. el cual relaciona con el Principio 17 de los PRDFI, y precisa que "especialmente aunque sin restringirse a ellos, en los casos de familias conformadas por sujetos de especial protección constitucional, niños, personas de la tercera edad, disminuidos físicos, o mujeres cabeza de familia, quienes tienen derecho a reencontrarse con sus familiares".

2. El derecho a una subsistencia mínima como expresión del derecho fundamental al mínimo vital, precisado en el Principio 18 PRDFI, lo cual significa que "las autoridades competentes deben proveer a las personas desplazadas, así como asegurar el acceso seguro de las mismas, (a) alimentos esenciales y agua potable, (b) alojamiento y vivienda bá- 
sicos, (c) vestidos apropiados, y (d) servicios médicos y sanitarios esenciales".

3. El derecho a la salud (artículo 49 C. P.) señalado en una jurisprudencia anterior a la que lo consagraría como derecho fundamental y vinculado con el principio 19 PRDFI.

4. El derecho a la educación básica hasta los quince años (artículo 67, inciso 3, C. P.). Para los niños en situación de desplazamiento, que explica la jurisprudencia va más allá de lo establecido en el Principio 23 PRDFl, por el mismo mandato constitucional.

5. Provisión de apoyo para el autosostenimiento (artículo 16 C. P.) por vía de la estabilización socioeconómica de las personas en condiciones de desplazamiento -obligación estatal fijada por la Ley 387 de 1997 y en los Principios 1, 3, 4, 11 y 18 PRDFI-.

6. El derecho al retorno y al restablecimiento, que implican unas obligaciones que con posterioridad a la sentencia se vienen definiendo por la jurisprudencia y por la ley, de manera específica por la Ley 1448 de 2011.

No se manifestó de manera concreta la T-025 respecto del derecho a la restitución, aunque sí hizo referencia en algunos de sus apartes a la situación de abandono de tierras por los desplazados, a la insuficiencia de información en los registros sobre tal situación y a la ausencia de mecanismos que protejan la propiedad o la posesión de las tierras de las personas desplazadas.
En el auto 218 de 2006 de seguimiento al cumplimiento de la T-025 de 2004, la Corte señala que dentro de los derechos específicos de las víctimas del conflicto armado se encuentra “(...) la protección de los bienes que han dejado abandonados, en particular de sus tierras - componente de protección que no ha sido resaltado con suficiente fuerza por las entidades que conforman el SNAIPD" (resaltado mío).

La sentencia T-821/2007, C. Botero, marca un hito importante de manera general en la consolidación de los derechos de las víctimas y de manera específica en cuanto al derecho a la restitución. Se sostiene en la sentencia que los derechos a la verdad, a la justicia y a la reparación "dan lugar a un conjunto de derechos fundamentales innominados de las víctimas (...) y constituyen uno de los contenidos específicos del derecho a la paz. (...) Adicionalmente, se trata de derechos que se encuentran garantizados en los tratados de derechos humanos y derecho internacional humanitario (...) hacen parte del bloque de constitucionalidad en sentido estricto, lo que les asigna el carácter de derechos fundamentales (...)".

Tales derechos los considera la sentencia como colectivos, su titular es la sociedad e igualmente son "derechos de las futuras generaciones a una vida sin violencia”. Su realización constituye una “importante garantía para la construcción de una sociedad democrática libre, al menos, de las más atroces formas de violencia".

Vinculado al derecho a la reparación integral se encuentra, según la sentencia que se viene 
comentando, el derecho a la restitución de los bienes de los cuales la persona ha sido despojada. Derecho a la reparación que de conformidad con la Corte Interamericana de Derechos Humanos se rige por el derecho internacional en todos sus aspectos.

La enunciación del derecho a la restitución lo hace la sentencia C-821/2007 en los siguientes términos:

Las personas que se encuentran en situación de desplazamiento forzado y que han sido despojadas violentamente de su tierra (de la tierra de la cual son propietarias o poseedoras), tienen derecho fundamental a que el Estado conserve su derecho a la propiedad o posesión y les restablezca el uso, goce y libre disposición de la misma en las condiciones establecidas por el derecho internacional en la materia. En efecto, en estos casos el derecho a la propiedad o a la posesión adquiere un carácter particularmente, reforzado, que merece atención especial por parte del Estado.

El carácter fundamental del derecho a la restitución lo deriva la Corte del derecho mismo a la reparación integral del daño causado a las víctimas de violaciones masivas y sistemáticas de derechos humanos. Siendo este un derecho fundamental, también lo es el derecho a la restitución de los bienes.

Insiste la Corte en que los Principios Pinheiro ${ }^{26}$ sobre la restitución de las viviendas y el patri-

26 Los Principios Pinheiro se derivan del Informe definitivo del Relator Especial, Sr. Paulo Sergio Pinheiro, Principios sobre la restitución de las viviendas y el patrimonio de los refugiados y las personas desplazadas, de la Comisión de Derechos Humanos de la ONU. monio de los refugiados y las personas desplazadas "hacen parte del Bloque de constitucionalidad en sentido lato, en tanto son desarrollos adoptados por la doctrina internacional, del derecho fundamental a la reparación integral por el daño causado" (C. P. art. 93.2).

Afirma la Corte que la política integral de la población desplazada va más allá de la atención humanitaria, comprendiendo la restitución o indemnización por los bienes y tierras despojadas independientemente del retorno o no de las víctimas y añade que, incluso como garantía de no repetición de los hechos criminales que causaron el despojo, se debe garantizar cuando las víctimas decidan el retorno la recuperación de los bienes despojados. Si no es posible la restitución del bien despojado la víctima tiene derecho a otro bien en reemplazo.

Sin embargo esta sentencia no se refiere al mecanismo que debería adoptarse para hacer efectiva la restitución. Solo hasta el auto 008 de 2009 la Corte planteó la necesidad de un mecanismo especial para definir las reclamaciones de restitución por parte de las víctimas del conflicto armado colombiano. En dicho auto la Corte ordena al Gobierno implementar una política de tierras con los siguientes objetivos:

(i) Contar con un mecanismo para esclarecer la verdad de la magnitud, las modalidades y efectos de los abandonos y despojos de tierras ocurridos en el marco del conflicto armado;

(ii) Identificar reformas institucionales y normativas que sean necesarias para asegurar la restitución de bienes a la población desplazada; 
(iii) Diseñar y poner en marcha un mecanismo especial para recibir, tramitar y resolver las reclamaciones de restitución de tierras de las víctimas de abandonos o despojos, teniendo en cuenta las distintas formas de relación jurídica de la población desplazada con los predios abandonados (propiedad, posesión, tenencia, etc.).

En el mismo auto comentado, la Corte sugiere al Gobierno considerar "El diseño de un mecanismo excepcional y expedito para resolver las reclamaciones sobre restitución de predios".

En la sentencia T-159/2011 insiste la Corte en el carácter fundamental del derecho a la restitución: “[I]as víctimas del desplazamiento forzado tienen el derecho fundamental a obtener la restitución y explotación de la tierra de la cual fueron privados y expulsados por situaciones de violencia que no estaban obligados a soportar y que desencadenó una vulneración masiva de sus derechos fundamentales..." (resaltado mío).

En vigencia de la Ley 1448, la Corte en el auto 219 de 2011 sugiere la necesidad de una nueva ruta del proceso de restitución de tierras consagrado en dicha Ley, en la que se revisen "Ias figuras del derecho civil y del derecho agrario que eventualmente pueden favorecer el despojo".

Al decidir sobre la constitucionalidad de algunas de las disposiciones de la Ley 1448 de 2011, la Corte Constitucional ${ }^{27}$ insiste en que de conformidad con el derecho internacional y el derecho internacional de los derechos humanos, la re-

27 CConst., C-715/2012, L. Vargas. paración a los desplazados "debe ser justa, suficiente, efectiva, rápida y proporcional a la gravedad de las violaciones y a la entidad del daño sufrido". Lo que implica en cuanto al derecho a la justicia “(iii) la obligación de establecer mecanismos de acceso ágil, oportuno, pronto y eficaz a la justicia para la protección judicial efectiva de los derechos de las víctimas de delitos".

El derecho a la reparación comprende, según la sentencia comentada "la restitución de las tierras usurpadas o despojadas a las víctimas", que es un componente esencial de dicho derecho, que al igual que los "derechos de las víctimas a la justicia, a la verdad y a las garantías de no repetición (arts. 2, 29, 93, 229, 250 numerales 6 y 7) son derechos fundamentales y por tanto de aplicación inmediata". ${ }^{28}$

\section{EL DERECHO A LA RESTITUCIÓN DE TIERRAS ABANDONADAS O DES- POJADAS COMO CONSECUENCIA DEL CONFLICTO ARMADO INTERNO ES UN DERECHO SOCIAL FUNDAMENTAL}

Del precedente jurisprudencial y normativo analizado previamente surge, sin lugar a dudas, que el derecho a la restitución del que venimos hablando es un derecho fundamental. Agregamos a lo dicho, que se trata de un derecho social fundamental en soporte de lo cual retomamos

Aunque no es tema del presente escrito, cabe destacar que la restitución es independiente de la decisión de retorno de la víctima restituida, ya que como bien se señala en los Principios Pinheiro, se ha ratificado por sentencias de la misma Corte Constitucional y está establecido en la Ley 1448 de 2011, el retorno es voluntario. Igualmente la Ley citada consagra la posibilidad de compensación en ciertas circunstancias que no permitan el retorno. 
las concepciones de Rodolfo Arango, de las que derivamos los siguientes componentes de dicho derecho:

1.- Una norma jurídica (M1). Derivada en primer lugar del precedente jurisprudencial, de la Ley 1448 y si se quiere de la misma Constitución colombiana, ya que siendo el derecho a la restitución parte integral del derecho a la reparación de las víctimas, este fue constitucionalizado en el Acto Legislativo $\mathrm{n}^{\circ} .1$ de 2012 en el incorporado artículo transitorio 66 que señala "Los instrumentos de justicia transicional serán excepcionales (...); y garantizarán en el mayor nivel posible, los derechos de las víctimas a la verdad, la justicia y la reparación".

2.- Una obligación jurídica (M2). Los derechos fundamentales son exigibles de manera directa e inmediata del Estado y por estar vinculados a la concepción liberal su objeto es, por regla general, una omisión. También pueden exigirse de los particulares cuando ejercen funciones públicas. Tratándose de los derechos sociales fundamentales Arango sostiene que el obligado solo puede ser el Estado por cuanto "las obligaciones positivas generales, correlativas a los derechos sociales fundamentales, no deben recaer en cabeza de particulares concretos por razones prácticas y morales". ${ }^{29}$ Sin embargo, lo que se aprecia en el derecho a la restitución es que los primeros obligados son los particulares que directa o indirectamente vulneraron dicho derecho, sacando cuando menos un provecho injusto de ello, y subsidiariamente el Estado cuando

29 Arango, ob. cit., p. 114 el particular contra quien se ejerce la acción acredita la buena fe exenta de culpa, caso en el cual de todas formas procede la restitución pero el particular es compensado.

3.- La posición jurídica (M3). Las víctimas del conflicto armado que se vieron impedidas de ejercer sus derechos de propiedad, o posesión sobre inmuebles; que fueron despojadas jurídica o materialmente de estos, e incluso aquellas que no pudieron continuar con la ocupación de bienes baldíos, tienen la potestad de exigir la restitución de los derechos que les fueron vulnerados; tal posición de víctimas les fue reconocida primero jurisprudencialmente y ahora en virtud de la Ley 1448 de 2011, siendo una de las finalidades de dicho reconocimiento hacerlas visibles dentro de la sociedad colombiana y el restablecimiento público de sus derechos sistemáticamente transgredidos.

4.- El grado de importancia (M4) del derecho a la restitución viene dado por la razón final precedentemente indicada, por cuanto tiene igualmente como finalidad la reconciliación nacional y el logro de la paz como un derecho y un deber de todos los colombianos.

5.- El carácter general positivo (M5). Esta característica del derecho social fundamental hace relación a las acciones positivas del Estado; no obstante, se plantea la discusión respecto de si este tipo de derechos podrían exigir también omisiones de parte de aquel. Las acciones positivas pueden ser fácticas o jurídicas, aunque de acuerdo con Arango, como objeto de los derechos sociales fundamentales solo entran en 
consideración las primeras. En el caso del derecho a la restitución del que venimos hablando, cabe destacar que se llega a él, en primer lugar, por la vía jurisprudencial, en la medida en que las circunstancias del conflicto armado interno llevaron a la necesidad de reconocer las situaciones jurídicas y fácticas que imponían la acción del Estado ante la violación generalizada de diversos derechos de las víctimas del conflicto, lo que de manera efectiva causaba daño individual a los ciudadanos.

Por otra parte, se dan las condiciones formales y materiales que justifican el derecho social fundamental, a las que se hizo referencia en el acápite primero de este escrito, ya que, en el caso concreto del conflicto armado, el Estado colombiano resultó desbordado y, teniendo la obligación jurídica y la posibilidad de proteger la vida, honra y bienes de todos los ciudadanos, dejó de hacerlo precisamente con una parte considerable de ellos que se encontraban en condiciones materiales inferiores, no solamente o exclusivamente económicas, pues como aparece demostrado, también fueron despojadas u obligadas a abandonar sus propiedades personas de reconocida capacidad económica. La omisión del Estado causó y sigue causando un daño injustificado a millones de colombianos.

El conflicto armado interno afectó de manera efectiva la libertad e igualdad de una buena cantidad de los habitantes del Estado colombiano, razón por la cual no solamente resultaban necesarias acciones positivas de este, sino que la situación de desigualdad generada exigía la consagración de acciones afirmativas como me- canismo idóneo para hacer efectivo el derecho conculcado, como se verá más adelante.

\section{EL PROCEDIMIENTO DE RESTI- TUCIÓN ESTABLECIDO EN LA LEY SE AJUSTA A LA EXIGENCIA DE LA NOR- MATIVIDAD INTERNACIONAL EN CUANTO A UN MECANISMO EXPEDI- TO PARA LA PROTECCIÓN DE LOS DE- RECHOS FUNDAMENTALES}

La Declaración Universal de Derechos Humanos consagra en el artículo 8 que “Toda persona tiene derecho a un recurso efectivo, ante los tribunales nacionales competentes, que la ampare contra actos que violen sus derechos fundamentales reconocidos por la constitución o por la ley" (resaltado mío).

Por su parte, la Convención Americana sobre Derechos Humanos dispone en el artículo 25:

Protección Judicial

Toda persona tiene derecho a un recurso sencillo y rápido o a cualquier otro recurso efectivo ante los jueces o tribunales competentes, que la ampare contra actos que violen sus derechos fundamentales reconocidos por la Constitución, la ley o la presente Convención, aun cuando tal violación sea cometida por personas que actúen en ejercicio de sus funciones oficiales.

La importancia del recurso efectivo, sencillo y rápido ha sido destacada por la Corte Interamericana de Derechos Humanos al advertir que:

constituye uno de los pilares básicos, no sólo 
de la Convención Americana, sino del propio Estado de Derecho en una sociedad democrática en el sentido de la Convención [...]. El artículo 25 se encuentra íntimamente ligado con la obligación general del artículo 1.1 de la Convención Americana, al atribuir funciones de protección al derecho interno de los Estados Partes". ${ }^{30}$

Y precisa que:

debe subrayarse que, para que tal recurso exista, no basta con que esté previsto por la Constitución o la ley o con que sea formalmente admisible, sino que se requiere que sea realmente idóneo para establecer si se ha incurrido en una violación a los derechos humanos y proveer lo necesario para remediarla ${ }^{31}$ (resaltado mío).

De conformidad con la jurisprudencia nacional citada en el acápite II, el hecho de calificar el derecho a la restitución de tierras despojadas o abandonadas por las víctimas del conflicto armado colombiano como un derecho fundamental exigía la consagración de un recurso efectivo, sencillo e idóneo que proveyera a remediar la grave situación presentada, la cual difícilmente podía resolverse dentro del ámbito del derecho ordinario, pues como lo declaraba la misma Corte Constitucional se requería "la revisión de figuras del derecho civil y del derecho agrario que eventualmente pueden favorecer el despojo". 32

30 Del caso Durán Ugarte, citado en el caso Cantoral Benavides vs. Perú, fallo de agosto 18 de 2000, párrafo 163.

31 Ibídem, párrafo 164.

32
Tal propósito se concreta en la Ley 1448 de 2011 al incorporar como uno de los mecanismos de reparación, el proceso de restitución de tierras.

\section{EL PROCESO DE RESTITUCIÓN DE TIERRAS DESPOJADAS O ABANDONA- DAS COMO UN RECURSO CONSTITU- CIONAL. CARACTERÍSTICAS}

Con fundamento en lo hasta aquí expuesto aventuramos afirmar que el proceso de restitución consagrado en la Ley 1448 de 2011 es una acción constitucional, enmarcada dentro de la justicia transicional, cuya finalidad exclusiva es hacer efectivo el derecho social fundamental a la restitución.

El carácter constitucional del proceso de restitución se refleja en:

1.- La aplicación directa de los Principios Rectores de los Desplazamientos Internos a que se refiere el Informe del Representante Especial del Secretario General de Naciones Unidas para el Tema de los Desplazamientos Internos, y entre ellos, los Principios sobre la restitución de las viviendas y el patrimonio de los refugiados y las personas desplazadas que hacen parte del bloque de constitucionalidad, conforme al artículo 93-2 de la Constitución Política, en términos de la jurisprudencia precedentemente citada.

En el artículo 27 de la Ley 1448 se da prevalencia a los convenios y tratados sobre derecho internacional humanitario y derechos humanos 
ratificados por Colombia por formar parte del bloque de constitucionalidad.

2.- La concepción de la acción constitucional conlleva aplicar y tener como criterios interpretativos los principios generales que rigen la Ley de Víctimas.

El primero de ellos es el principio pro homine o "de favorabilidad pro víctima" derivado, entre otros, del artículo 27 de la Ley, y que implica que las víctimas puedan participar en el proceso judicial con plena garantía de sus derechos y en el trámite de postrestitución, con la seguridad de que sus intereses serán realmente atendidos. De manera concreta y para efectos del proceso de restitución, este principio exige al juez transicional aplicar las normas o interpretaciones que más favorezcan la dignidad humana y los derechos de las víctimas.

El principio de la buena fe establecido en el artículo 5 de la Ley señala que la víctima podrá acreditar el daño sufrido, "por cualquier medio legalmente aceptado" y que bastará a la víctima "probar de manera sumaria el daño sufrido" para que sea relevada de la carga de la prueba. De manera concreta, en cuanto tiene que ver con el proceso de restitución se estipula en el artículo 78 de la Ley que "Bastará con la prueba sumaria de la propiedad, posesión u ocupación y el reconocimiento como desplazado en el proceso judicial, o en su defecto, la prueba sumaria del despojo, para trasladar la carga de la prueba al demandado o a quienes se opongan a la pretensión de la víctima en el curso del proceso de restitución".
El artículo 73, numeral 8, consagra de manera concreta el principio de prevalencia constitucional con el fin de garantizar "la prevalencia de los derechos de las víctimas del despojo y el abandono forzado que tengan un vínculo especial constitucionalmente protegido, con los bienes de los cuales fueron despojados". Con base en este principio se debe privilegiar "a las víctimas más vulnerables, y a aquellas que tengan un vínculo con la tierra que sea objeto de protección especial".

El artículo 7 sobre el debido proceso como principio de la ley indica que se "debe garantizar un proceso justo y eficaz".

3.- La solicitud de restitución puede ser presentada oralmente o por escrito (art. 83), directamente por los titulares de la acción, a través de apoderado o de la Unidad de Restitución de Tierras, en condiciones similares a la acción tutela.

4.- Las presunciones específicamente establecidas para tener por probado el hecho del despojo o abandono forzado de tierras, y la inversión de la carga de la prueba en circunstancias específicas, aleja también el proceso analizado del simple proceso de pertenencia del derecho civil para el cual tales figuras resultan casi que inverosímiles, sobre todo en estados de derecho en los que prima la normalidad.

Tales presunciones tienen como finalidad, por una parte, hacer efectivo el derecho a la igualdad, perdido como consecuencia del conflicto armado, y alcanzar la justicia material que mu- 
chas veces se dificulta con las formalidades propias de los procesos ordinarios.

Estos instrumentos, consagrados en el artículo 77 de la Ley de Víctimas, impiden que la sola existencia de contratos suscritos con cumplimiento de todas las formalidades legales, sentencias debidamente ejecutoriadas o actos administrativos en firme permitan a sus titulares alegar buena fe exenta de culpa cuando los inmuebles adquiridos con base en estos instrumentos lo hayan sido en situación de violencia, generando concentración de la tierra y alterando su uso, o en el caso de compraventa en circunstancias de lesión enorme respecto de la cual se produzca incluso la formalidad del saneamiento.

5.- Las facultades concedidas al juez de restitución, juez transicional, son evidencia también del carácter especial del proceso en comento, más próximas a las del juez constitucional que a las del juez de la jurisdicción civil, el cual, muy a pesar de los avances realizados, sigue siendo un juez con potestades principalmente dispositivas.

El juez transicional tiene como función principal revertir el desequilibrio y la asimetría que existe entre las víctimas y quienes puedan pretender un mejor derecho sobre el inmueble objeto de restitución. Lo cual de suyo difiere de la igualdad de armas que presupone el proceso civil. Los artículos 13, 114 y 115 de la Ley 1448 reconocen el enfoque diferencial que debe ser tenido en cuenta en el proceso. A manera de ejemplo: el artículo 114 consagra el requisito de "atención preferencial" para mujeres.
Con fundamento en la situación de vulnerabilidad de las víctimas el juez debe dar trámite preferente de sus reclamaciones, según lo dispone el artículo 85 de la Ley.

Establece también la Ley diversas medidas cautelares para la protección del predio objeto de la restitución y para los mismos solicitantes, las cuales está obligado a adoptar el juez cuando resulte necesario. Así por ejemplo, debe el juez decretar la sustracción provisional del inmueble del comercio (art. 86), lo que equivale al embargo propio de los procesos de ejecución, u ordenar medidas de protección al solicitante si la solicitud de restitución afecta sus condiciones de seguridad personal.

Está igualmente facultado el juez para declarar la nulidad de actos administrativos que hayan legalizado una situación jurídica contraria a los derechos de la víctima sobre el bien objeto de restitución, con el consecuente decaimiento de todos los actos administrativos posteriores y la nulidad de todos los actos y negocios jurídicos privados que recaigan sobre la totalidad o parte del predio.

También podrá el juez revocar las decisiones judiciales a través de las cuales se vulneraron los derechos de la víctima sobre el inmueble objeto de restitución, y ordenar los ajustes tendientes a implementar y hacer eficaz la decisión favorable a la víctima (art. 74).

Tiene el juez la potestad de suspender procesos o de acumular aquellos relacionados con el predio cuya restitución se solicita, tales como: de- 
clarativos de derechos reales, de pertenencia, posesorios de cualquier naturaleza, procesos sucesorios, divisorios, de deslinde y amojonamiento, de servidumbres, de restitución de tenencia, de bienes vacantes y mostrencos, y de embargo, salvo los procesos de expropiación. El artículo 95 de la Ley que establece esta potestad señala de manera expresa como finalidad de esta "obtener una decisión jurídica y material con criterios de integralidad, seguridad jurídica y unificación para el cierre y estabilidad de los fallos."

Sin embargo, la posibilidad de acumular procesos de diferente índole (civiles y administrativos) puede afectar la celeridad de la restitución, distrayendo la finalidad de esta. A manera de ejemplo: adelantar procesos de filiación o sucesión que exigen el cumplimiento de las formalidades que las normas procesales les han establecido a cada uno de ellos, y que tal vez no podrían se obviadas por el juez de restitución sin posibles afectaciones al debido proceso y al derecho de defensa, podría dilatar necesariamente el trámite de restitución.

Por último, el juez transicional, al igual que en las acciones constitucionales, mantiene la competencia (parágrafo $1^{\circ}$, art. 91 y art. 102 de la Ley) para garantizar el goce efectivo de los derechos del reivindicado, verificar el cumplimiento de la sentencia de restitución proferida y de las órdenes impartidas, pudiendo fijar mandatos adicionales a los contenidos en el fallo original. De acuerdo con la primera de las normas citadas, dicha "competencia se mantendrá hasta tanto estén completamente eliminadas las cau- sas de la amenaza sobre los derechos del reivindicado en el proceso".

Sobre el particular ha dicho la Corte Constitucional:

Estas facultades del juez de restitución, ratifican que la naturaleza del proceso de restitución no se circunscribe a la resolución de la cuestión litigiosa, sino que le otorga además facultades especiales a los jueces para que adopten todas las medidas que sean necesarias para garantizar el cumplimiento del fallo, asegurar la restitución material y jurídica del predio a quien fuera víctima del despojo, así como precaver los riesgos de despojo futuros. ${ }^{33}$

6.- El artículo 93 de la Ley preceptúa que "Las providencias que se dicten se notificarán por el medio que el Juez o Magistrado considere más eficaz", lo que resulta entendible dada la pretensión de celeridad del proceso que se procura, evitando los engorrosos trámites y las dilaciones que se generan con las formalidades en la notificación que se consagran en jurisdicciones diferentes a la constitucional.

7.- Con la misma finalidad de celeridad y eficacia en el trámite, la Ley de Víctimas proscribe instituciones que son caras a los procesos de las jurisdicciones ordinarias y especialmente de la civil. De manera concreta, el artículo 94 señala como no admisibles "la demanda de reconvención, la intervención excluyente o coadyuvante, incidentes por hechos que configuren excepciones previas, ni la conciliación" y dispone que

33 CConst., C-099/2013, M. Calle. 
cuando quiera que sean propuestas la autoridad judicial debe rechazarlas de plano mediante auto no susceptible de recursos.

8.- El carácter expedito del proceso se refleja en el hecho de haber sido consagrado como de única instancia con solo dos circunstancias que permiten la revisión de los fallos proferidos: a) cuando se trata de procesos sin oposición, los cuales son fallados por los jueces civiles del circuito especializados en restitución de tierras. Si la decisión niega la solicitud de restitución procede la consulta automática del fallo ante la Sala del tribunal especializada en restitución de tierras (art. 79 de la Ley); b) los procesos con oposición, decididos por la Sala Especializada en Restitución de Tierras, pueden ser objeto del recurso de revisión ante la Sala de Casación Civil de la Corte Suprema de Justicia, en los términos de los artículos 379 y siguientes del Código de Procedimiento Civil (art. 92 de la Ley).

La consagración del proceso como de única instancia y su brevedad dio lugar a una demanda de inexequibilidad, la cual fue definida por la Corte Constitucional a favor de las normas que lo regulan con los siguientes argumentos, entre otros:

No obstante su brevedad, el legislador dio garantías suficientes para que quienes tengan interés puedan intervenir en el proceso, solicitar pruebas y controvertir las que hayan sido presentadas.

(...)

Adicionalmente, contrario a lo que afirman los accionantes, la ley sí prevé la posibilidad de controvertir decisiones adversas, tanto durante la etapa administrativa, al exigir que el acto administrativo que resuelve la inscripción del predio sea un acto motivado, y por lo mismo controvertible a través de los recursos de ley; como en la etapa judicial, al autorizar la procedencia de recursos como el de revisión, que permite cuestionar las decisiones adoptadas en el proceso de restitución si aparecen pruebas que evidencien que hubo fraude; o la consulta, para controvertir la decisión judicial que niega la restitución.

Por lo anterior, encuentra la Corte que a pesar de tratarse de un procedimiento de única instancia, con términos breves, dado que dentro del mismo el legislador previó suficientes garantías a los derechos al debido proceso, de defensa, a la igualdad y al acceso a la justicia, las limitaciones establecidas resultan razonables y proporcionadas y no son contrarias al principio de doble instancia. ${ }^{34}$

\section{9.- El término perentorio de cuatro meses para} decidir el proceso, consagrado en el artículo 91, parágrafo segundo de la Ley 1448 de 2011, constituye sin lugar a dudas otra razón de similitud entre el proceso de restitución y las acciones constitucionales. La misma norma señala que el incumplimiento de estos términos constituirá falta gravísima.

10.- Por último, y no menos importante, la Ley de Víctimas permite que las solicitudes del proceso de restitución sean colectivas (art. 82), es decir, que comprendan diversos titulares o varios predios, cuando las circunstancias del des-

34 CConst., C-099/2013, M. Calle. 
pojo o abandono fueron comunes, con lo cual respecto de un fenómeno que ha sido colectivo se crea un instrumento de resarcimiento de similar naturaleza, situación que hace afín este proceso con las acciones de grupo.

\section{IMPLICACIONES DE CONCEBIR EL PROCESO DE RESTITUCIÓN COMO UNA ACCIÓN CONSTITUCIONAL ME- DIANTE LA CUAL SE PROTEGE UN DE- RECHO SOCIAL FUNDAMENTAL}

El hecho de ser el proceso de restitución de tierras consagrado en la Ley 1448 de 2011 una acción constitucional, cuya finalidad es la protección de un derecho social fundamental, tiene implicaciones interpretativas que resultan de la mayor importancia habida cuenta que la Ley no reguló ni pretendió regular al detalle todos los aspectos propios de un proceso judicial.

Por lo expuesto, consideramos que la perspectiva hermenéutica debe tener en cuenta la finalidad del legislador al regular el proceso dentro del marco de una ley para las víctimas del conflicto armado interno.

Entendemos que el legislador pretendió de manera específica, en lo que hace al proceso de restitución, consagrar una acción afirmativa que equilibrara la desigualdad material y jurídica a la que se enfrentaban las víctimas, lo cual se constata en las siguientes figuras expresamente incorporadas a la Ley: el establecimiento del principio pro homine o pro víctima ya mencionado, la presunción de la buena fe de las víctimas, la presunción de fidedignidad de las pruebas aportadas por la Unidad de Restitución de Tierras, la inversión de la carga de la prueba dentro del proceso, la presunción de derecho consagrada en el numeral $1^{\circ}$ del artículo 77 de la Ley, cuando el opositor en el proceso sea una persona condenada por pertenencia, colaboración o financiación de grupos armados que actúan por fuera de la ley, cualquiera que sea su denominación, o por narcotráfico o delitos conexos o un tercero vinculado con el opositor, y las presunciones legales igualmente señaladas en el artículo 77 ya mencionado, entre las más importantes.

De manera que el juez en el proceso tendrá frente a sí el derecho social fundamental a la restitución, las reglas establecidas por la Ley 1448 de 2011, el derecho a la igualdad de manera específica y concreta, y los demás derechos y principios constitucionales de manera general, como herramientas a primera mano para resolver los problemas que puedan presentársele en la definición de los casos específicos.

Lo anterior para decir que el proceso de restitución no es un proceso ordinario, o un proceso civil cuyos vacíos deban ser resueltos de manera principal y exclusiva acudiendo al derecho civil, al derecho agrario o a las normas del procedimiento civil, sin que tampoco deban tenerse como inaceptables. No estamos frente a una jurisdicción civil, sino constitucional.

Esta afirmación se realiza muy a pesar de que el artículo 79 de la Ley 1448 señale que quienes deciden los procesos de restitución son magis- 
trados de Sala Civil y jueces civiles de circuito especializados en restitución de tierras y que el artículo 119 de la misma Ley tenga una declaración en condiciones parecidas.

De las normas mencionadas no puede pretender derivarse que el proceso de restitución es un proceso civil, respecto del cual inexorablemente deben aplicarse en lo no regulado por la Ley las normas del procedimiento civil. Conviene precisar, que si bien la situación objeto de litigio en principio afecta derechos patrimoniales entre particulares, lo cierto es que el hecho de: estar directamente involucrado un derecho social fundamental, el alcance de la restitución, las circunstancias generadoras del despojo o abandono, la posibilidad de que se vean también vinculados intereses patrimoniales del Estado y la misma imposición de realizar el objeto de la Ley en el marco de la justicia transicional conllevan a afirmar que el proceso trasciende el ámbito de la jurisdicción civil.

Como se dijo al inicio de este escrito, la Ley 1448 de 2011 no hace una remisión general al Código de Procedimiento Civil, solo lo hace para unas materias específicas, y tal situación se justifica por las mismas razones que se han dado en el precedente jurisprudencial ya explicado en cuanto a que las figuras del derecho civil y del derecho agrario eventualmente pueden favorecer el despojo. Adicionalmente, cabe afirmar que los procedimientos ordinarios van en contravía de la exigencia del derecho internacional respecto de un procedimiento efectivo y expedito para la protección de los derechos fundamentales.
Por tanto, la hermenéutica de las normas sobre el proceso de restitución debe ser constitucional, basada en principios y ponderación de derechos fundamentales.

A manera de ejemplo referiremos algunas situaciones que han generado inquietudes interpretativas, que entendemos se resuelven en la forma precedentemente indicada.

a.- El artículo 97 de la Ley 1448 consagra la alternativa de la compensación cuando la restitución no sea posible, y señala las circunstancias puntuales en las cuales puede producirse la compensación, lo que ha llevado a interpretar que se trata de unas causales taxativas por fuera de las cuales la compensación no sería legalmente permitida. Sin embargo, pueden presentarse situaciones en las que cabría preguntar si no resulta válido ordenar la compensación. Tal el caso de una víctima respecto de la cual se establece que efectivamente tiene el derecho a la restitución, pero que por las condiciones socioeconómicas del lugar del inmueble el retorno no cumpliría con la condición de la vocación transformadora de la restitución. Esta situación no está contemplada dentro de las causales para la restitución por equivalente o para la compensación en dinero, ¿se debe ordenar la restitución a sabiendas de que el inmueble será abandonado y que la víctima no será reparada de manera integral?

b.- En los casos de despojo o del desplazamiento forzado que perturban la explotación económica de un baldío, el artículo 74 de la Ley 
establece que el magistrado deberá acoger el criterio sobre la unidad agrícola familiar (UAF) como extensión máxima a titular y será ineficaz cualquier adjudicación que exceda de esta extensión, pero nada dice respecto a inmuebles objeto de restitución por debajo de la UAF. Esta circunstancia tampoco está contemplada como causal de compensación, ¿se puede ordenar la restitución del inmueble a pesar de no cumplir con la condición mencionada?

c.- De acuerdo con el artículo 91 de la Ley, procede la compensación para el opositor que haya acreditado la buena fe exenta de culpa. ¿Cabría la posibilidad de que en ciertas condiciones particulares no se exigiera al opositor acreditar la buena fe exenta de culpa?, por ejemplo, cuando el opositor sin alcanzar la condición de víctima se encontraba en condiciones sociales y económicas similares a aquella y no propició ni se aprovechó de manera directa del abandono del predio por la víctima.

El primero de los ejemplos hace referencia a una situación que aparece resuelta en la Ley de una manera que hace nugatorio el derecho de restitución de la víctima, lo que obligaría a una interpretación de la regla de manera que no haga inocuo el derecho social fundamental protegido y se cumpla con el principio establecido en el artículo 25 de la Ley de Víctimas, según el cual la reparación deber ser transformadora y efectiva.

En el segundo ejemplo, la situación planteada no aparece resuelta expresamente por la
Ley, pero igualmente debería serlo teniendo en cuenta la calidad de principios del cual gozan los derechos fundamentales, y los otros principios consagrados en la misma Ley 1448 como el pro homine, en virtud del cual las normas debieran ser interpretadas de la forma que más favorezca a las víctimas.

El último ejemplo parecería definitivamente resuelto por la Ley en la medida que aparenta no admitir excepciones. Sin embargo, consideramos que en ciertas situaciones la carga de demostrar la buena fe exenta de culpa pudiera vulnerar el derecho fundamental a la igualdad constitucionalmente consagrado, caso en el cual, el juzgador está en la obligación de realizar una ponderación que sin afectar los derechos de las víctimas garantice el de la igualdad. En este evento el test de razonabilidad puede resultar útil para determinar las circunstancias excepcionales en las que no se exigiría la carga de la prueba de la buena fe exenta de culpa. Se debería verificar la proporcionalidad en relación con la finalidad perseguida, esto es, efectuar una ponderación en el caso concreto, de las consecuencias del trato diferencial que implica exigir la prueba de la buena fe exenta de culpa. En últimas, hacer un examen de la razonabilidad de la exigencia en las circunstancias propias del trámite objeto de resolución.

\section{CARÁCTER MIXTO DEL PROCESO. EL TRÁMITE ADMINISTRATIVO}

Una de las connotaciones del proceso de restitución es su carácter mixto, que contempla dos 
trámites consecutivos y complementarios: uno administrativo y otro judicial, y la correspondiente intervención de las dos ramas del poder público. El primero de los trámites, el administrativo, constituye según la Ley requisito de procedibilidad para el judicial, y la autoridad administrativa que adelanta la primera parte puede constituirse en interviniente en el segundo trámite, en la medida que está llamada a actuar en nombre de las víctimas que procuran la restitución y como opositor en ciertas circunstancias.

La Unidad Administrativa Especial de Gestión de Restitución de Tierras Despojadas es el ente creado por la Ley para adelantar el trámite administrativo, el cual concluye con la inscripción en el "Registro de tierras despojadas y abandonadas forzosamente" de los predios despojados y abandonados, las personas que padecieron tal situación y su relación jurídica con aquellos. ${ }^{35}$

Aunque no es el objeto principal de este escrito, debemos destacar que la Ley de víctimas no hace una remisión expresa en cuanto a las normas aplicables para el trámite en comento. Sin embargo, el Decreto 4829 de 2012, reglamentario de la Ley sobre el particular, remite al Código Contencioso Administrativo, hoy Código de Procedimiento Administrativo y de Io Contencioso Administrativo, de manera específica en temas como la naturaleza de las decisiones en las actuaciones relacionadas con el registro de tierras despojadas y abandonadas forzosamente, notificaciones, agotamiento de la vía gubernativa, y en el artículo 29 de la norma regla-

35 Artículo 76, Ley 1448 de 2011. mentaria se hace una remisión general cuando se dice que "En las actuaciones administrativas del Registro, en lo no previsto por la Ley 1448 de 2011, se aplicarán las disposiciones del Código Contencioso Administrativo que se relacionen con la materia o de la norma que lo sustituya".

Resulta importante hacer notar que en el artículo 27 de la norma reglamentaria en comento se establece que "Una vez agotada la vía gubernativa, el solicitante que no haya sido incluido en el Registro, podrá acudir ante la Jurisdicción de lo Contencioso Administrativa en ejercicio de la acción de nulidad y restablecimiento del derecho", lo cual, en nuestro criterio, contraría los principios y criterios que en la Ley regulan el proceso de restitución, primero por cuanto la norma mencionada se refiere al solicitante no incluido en el registro; la Ley, por su parte, contempla dos situaciones: el registro del predio y el registro de los solicitantes.

Solo el no registro del predio que implica también la negativa de la inscripción de los solicitantes justifica recurrir a la jurisdicción contenciosa, ya que no se cumpliría con el requisito de procedibilidad para poder acudir al trámite judicial de restitución. Por el contrario, el registro del predio y la negativa de la inscripción de uno o algunos de los solicitantes pueden resolverse con la participación de este o estos en el proceso judicial de restitución como opositor o como tercero.

En el presupuesto establecido por la norma reglamentaria analizada podría acontecer que la decisión tomada dentro del proceso de restitu- 
ción (muy posiblemente anterior a la del proceso contencioso), se pudiera ver afectada por una posterior decisión del proceso contencioso contrariando la finalidad fijada por la Ley 1448 en cuanto a "una decisión jurídica y material con criterios de integralidad, seguridad jurídica y unificación para el cierre y estabilidad de los fallos".

Para atender esta situación habría lugar a aplicar las facultades del juez de restitución para acumular procesos, pudiendo atraer tal acción contenciosa con el fin de prevenir la situación adversa aquí comentada.

\section{CONCLUSIONES}

1.- El proceso de restitución de tierras despojadas o abandonadas, consagrado en la Ley Víctimas, es uno de los instrumentos más importantes diseñados por esta Ley en procura de la "reparación integral" a las víctimas del conflicto armado colombiano.

2.- La finalidad del proceso de restitución es la protección de un derecho social fundamental, lo que le da la connotación de acción constitucional, característica reforzada por su remisión al bloque de constitucionalidad, por las acciones afirmativas que consagra a favor de las víctimas, por el carácter breve y efectivo que quiere imprimírsele y por los amplios poderes que confiere a los jueces y magistrados de restitución.

3.- El derecho a la restitución no es igual al derecho a la propiedad, no tiene la amplitud que tradicionalmente se predica del derecho a la propiedad pero refleja de manera real y específica la forma como una buena mayoría de los colombianos se ha relacionado con la tierra. Lo que busca el proceso de restitución de tierras es reconocer esas realidades, trascenderlas a través de la función transformadora y equipararlas a la concepción clásica de propiedad sobre la tierra.

4.- Muy a pesar de la tipología asignada a los jueces y magistrados que conocen del proceso de restitución, que pudiera hacer pensar que se trata de un proceso de carácter civil con remisión a la normativa que los regula, el derecho social fundamental objeto de protección, la flexibilidad que pretende imprimírsele y la proscripción de figuras propias del derecho ordinario que pudieran afectar tal finalidad Ileva a concluir que, como ya se tiene dicho, se trata de una acción constitucional.

5.- El carácter constitucional de la acción de restitución tiene una incidencia fundamental en la interpretación de las normas que la regulan, lo que implica la confrontación de reglas con derechos fundamentales y principios constitucionales con miras a la efectiva realización del derecho objeto de protección.

Desde esta perspectiva constituyen criterios de interpretación: a) la concepción constitucional de la función social de la propiedad; b) la prevalencia de la interpretación finalística - principio pro homine-; c) los principios del derecho internacional; y d) la integración normativa con las acciones constitucionales y subsidiariamente 
con el derecho agrario, el Código Civil y el Código de Procedimiento Civil.

6.- La potestad/deber de los jueces y magistrados de conservar la competencia después del fallo se constituye en un instrumento fundamental que, adecuadamente usado por aquellos, podrá garantizar que las decisiones judiciales se hagan efectivas, cumplir con la finalidad transformadora de la restitución y que se procure la adecuada protección a quienes sean restituidos en sus derechos previniendo su revictimización.

7.- Al ser el trámite administrativo un requisito de procedibilidad de la acción judicial, esta última podría estar condicionada por aquel incidiendo en la efectiva realización del derecho social fundamental protegido.

8.- Una de las características del proceso hace referencia a la celeridad que pretende dársele, estableciendo un término perentorio para su resolución. Sin embargo, la pretensión de restituir el derecho mediante "una decisión jurídica y material con criterios de integralidad, seguridad jurídica y unificación para el cierre y estabilidad de los fallos", lo que implica la posibilidad y la necesidad de acumular diversos tipos de procesos y trámites, dificultan y pueden dar al traste con la muy loable pretensión de celeridad y efectividad.

\section{Bibliografía}

ALEXY, Robert. Tres escritos sobre los derechos fundamentales y la teoría de los principios. Bogotá: Universidad Externado de Colombia, 2003.
ARANGO RIVADENEIRA, Rodolfo. El concepto de derechos sociales fundamentales. $2^{\circ}$ ed. Bogotá: Legis, 2012.

. Derechos humanos como límite a la democracia análisis de la ley de justicia y paz. Bogotá: Norma, 2008.

COLOMBIA. CORTE CONSTITUCIONAL: T-025 de 2004, Auto 218 de 2006, T-821/2007, Auto 008 de 2009, T-159/2011, Auto 219 de 2011, C-052/2012, C-250/2012, C253/2012, C-715/2012, C-785/2012, C-099/2013, C-462/2013.

CORTE INTERAMERICANA DE DERECHOS HUMANOS. Caso Cantoral Benavides vs. Perú, fallo de agosto 18 de 2000; Caso Forneron e Hija vs. Argentina, sentencia de 27 de abril de 2012; Caso Aloeboetoe y otros vs. Surinam, sentencia de 10 de septiembre de 1993.

GAMBOA TAPIAS, Camila de (editora académica). Justicia transicional: teoría y Praxis. Colección Textos de Jurisprudencia. Bogotá: Universidad del Rosario, 2006.

GARAY SALAMANCA, Luis Jorge y VARGAS VALENCIA, Fernando. Memoria y reparación. Elementos para una justicia transicional pro víctima. Bogotá: Universidad Externado de Colombia, 2012.

GARAY, Luis Jorge. Reparar de manera integral el despojo de tierras y bienes. En: El reto ante la tragedia humanitaria del desplazamiento forzado. Vol. 5. Bogotá: Embajada de Países 
Bajos, 2009.

NACIONES UNIDAS. COMITÉ DE DERECHOS HUMANOS. Observación general $n^{\circ}$. 31. Naturaleza de la obligación jurídica general impuesta a los Estados Partes en el Pacto. Documento: CCPR/C/21/Rev.1/Add.13, 26 de mayo de 2004.

NACIONES UNIDAS. Conjunto de principios para la protección y la promoción de los derechos humanos mediante la lucha contra la impunidad. Documento E/CN.4/2005/102/Add.1., 8 de febrero de 2005. - Informe de la Alta Comisionada para los Derechos Humanos sobre la situación de los derechos humanos en Colombia. Documento A/HRC/22/17/Add.3, 7 de enero de 2013. - Informe del Relator Especial sobre la promoción de la verdad, la justicia, la repa- ración y las garantías de no repetición. Documento A/67/368, 13 de septiembre de 2012.

. Principios y directrices básicos sobre el derecho de las víctimas de violaciones manifiestas de las normas internacionales de derechos humanos y de violaciones graves del derecho internacional humanitario a interponer recursos y obtener reparaciones. Documento A/RES/60/147, 21 de marzo de 2006.

RODRÍGUEZ GARAVITO, César y RODRÍGUEZ FRANCO, Diana. Cortes y cambio social. Cómo la Corte Constitucional transformó el desplazamiento forzado en Colombia. Bogotá: Antropos, 2010.

UPRIMNY YEPES, Rodrigo et al. ¿Justicia transicional sin transición? Verdad, justicia y reparación para Colombia. Bogotá: Dejusticia, 2006. 